\title{
Social Media Usage Patterns in Higher Education Institutions - An Empirical Study
}

\author{
https://doi.org/10.3991/ijet.v14i05.9720 \\ Yanka Aleksandrova $\left.{ }^{(}\right)$, Silvia Parusheva \\ University of Economics Varna, Varna, Bulgaria \\ yalexndrova@ue-varna.bg
}

\begin{abstract}
The main goal of this research is to identify some notable trends, opportunities and limitations regarding the application of social media in higher education based on studying the way students use social media during their education. The research is focused on the impact of social media on the process of learning, creation and distribution of education related content, as well as on education related communication. The target groups of the research are students in University of Economics - Varna enrolled in different bachelor and master programs.

An association analysis was implemented to identify the most common patterns regarding the application of social media in the education process. Statistical methods for testing hypothesis were used to assess the relationship between students' specialty and derived social media patterns.

The findings show that Facebook groups are a preferable social media tool for communication with colleagues, content sharing and distribution, while wikis and university Learning Management Systems (LMSs) are most used for content creation and additional learning. Some social media channels are more preferable for content creation and additional learning compared to scientific databases and e-books.

Following the research results a conclusion can be drawn regarding the leading part of the students in initiating the use of social media compared to the relatively smaller role of the academic staff in this process. A medium to small relationships were discovered between students' specialty and the application of content sharing communities and forums in knowledge process with students in computer science more likely to use these social media types compared to students in economics.
\end{abstract}

Keywords-Social media, higher education, social networks, Facebook groups, association rules, content sharing communities, wikis, forums

\section{Introduction}

Social media unambiguously has a great impact on all areas of modern life. It's changed not only the way people communicate, express themselves and share, but also the social and public life. Undoubtedly, all areas of our lives in one degree or another have changed under the influence of social media. The strongest and most visible 
changes were observed in the young generations. In 2018, for example, $64 \%$ of the active members of the largest social network Facebook are aged up to 34 years [1].

Through the new opportunities of the different social media like social networking sites, collaborative projects, blogs, wikis, communities, forums, content platforms, etc., young people not only communicate freely, but also can create and share their feelings, opinions and emotions. One of the areas which experienced the inevitable changes under the growing use of social media, is higher education. On the one hand, students continue to use social media in universities as well as any other sphere of their lives. On the other hand, educators embrace the opportunities of social media to engage students in the process of creating and sharing knowledge and in more efficient ways of communication.

In addition, the development of the university electronic Learning Management Systems (eLMS) led to more embed functionalities intrinsic to social media. E-learning systems are no longer used solely as a platform for access to teaching materials, but also provide a considerable part of the social media capabilities as a medium for communication (messaging, forums), co-creation of content (wiki, blogs), etc. While the use of social media like Facebook, Twitter, Google +, etc. in universities is predominately initiated by students, the leading responsibility for using the eLMS is to faculty staff and universities as a whole.

\section{$2 \quad$ Literature Review}

The impact of social media on the educational process is explored by different researches. Some drivers for the application of social media in higher education are studied by Dumpit and Fernandez [2]. By applying Technology Acceptance Model the authors demonstrate that main factors for social media usage in higher education are perceived ease of use, subjective norm, and perceived playfulness. Liu at al. [3] studied the impact of perceived value, perceived enjoyment and perceived influence on adopting social networking sites (SNS) by students. Their results support the hypothesis that there is a strong correlation between perceived value and intentions to use SNS and found moderate correlation between perceived influence and respectively enjoyment and those intentions. Lau [4] explores the effect of using social media on academic performance as measured by grade point average. The findings suggest that using social media for academic purposes is not a significant predictor of academic performance. At the same time, using social media for non-academic purposes has a negative impact on students' academic performance. Manca and Ranieri [5] explore some advantages and obstacles for the use of social media from academic staff. According to their research, social media use is still limited and restricted and is not well adopted in the teaching process. However, there are some differences among the academic staff in the ways they use social media regarding scientific disciplines of teaching. Chawinga [6] argues that the proper deployment of Twitter and blogs could facilitate a learner-centered approach to teaching. Results show that the opportunities to discuss and share amongst themselves and with their teacher $24 / 7$ benefits the educational process. Tang et al. [7] also examine the use of the microblogging platform Twitter and conclude that 
this social media could improve learning outcomes especially as a "push" technology and a peer interaction platform. Despite the challenges, the authors think that Twitter could facilitate communication and interaction. Moore-Russo et al. [8] analyze the interactions in an academic Facebook group. Their case study's results confirm that Facebook is primarily a platform for entertainment and socialization, but at the same time it can give a clear advantage for the content creation process.

A comparison between Facebook, Moodle platforms and traditional paper-based approach for learning and assessment has been drawn by Jeljeli et al. [9]. The results of their study reveal that Moodle is a preferable learning as well as assessment tool compared to the other two explored approaches. The benefits of using social networking sites as an additional learning resource is researched by Arouri [10] who explores the students' perceptions before and after the application of dedicated Facebook page during an educational course. The author reveals some of the challenges regarding usage of Facebook as a learning resource such as poor internet access, difficulty in meeting the course requirements and lack of computer skills.

\section{$3 \quad$ Method}

The current study is focused on the way students use social media for academic purposes. Two main topics have been chosen, namely the communication and knowledge process. Each one of the two main topics have been divided into subtopics as depicted on figure 1 .

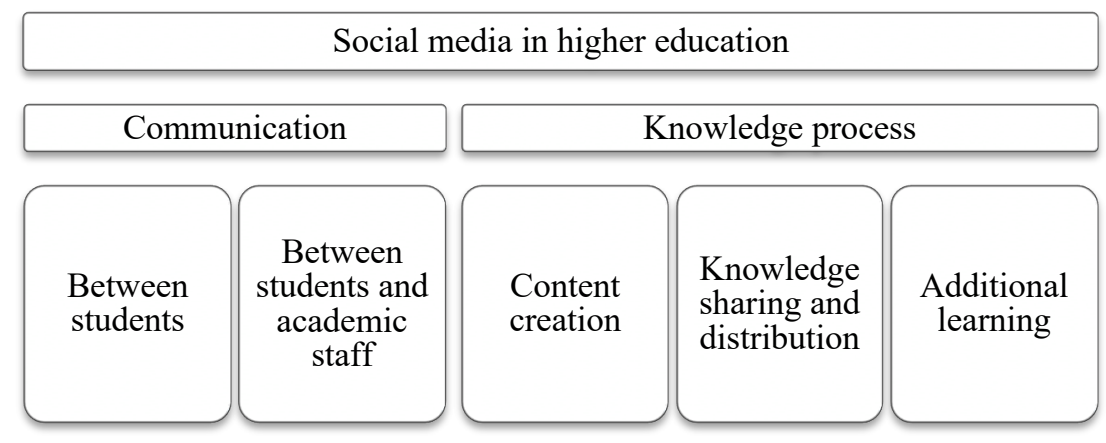

Fig. 1. Topics and subtopics of the research

An online survey has been designed and deployed in order to collect students' responses. Students pointed out their bachelor or master degree program and course of education. The usage of social media is identified with questions about social media profiles and the frequency of usage of the most popular social networks Facebook, Twitter, LinkedIn, Google +, YouTube, Reddit, Flickr, Instagram, Snapchat, forums. Students can enter also a free text option „Other” in case they use not listed social media. 
Based on the topics and subtopics of the study, the stages of the research process were established as shown on figure 2.

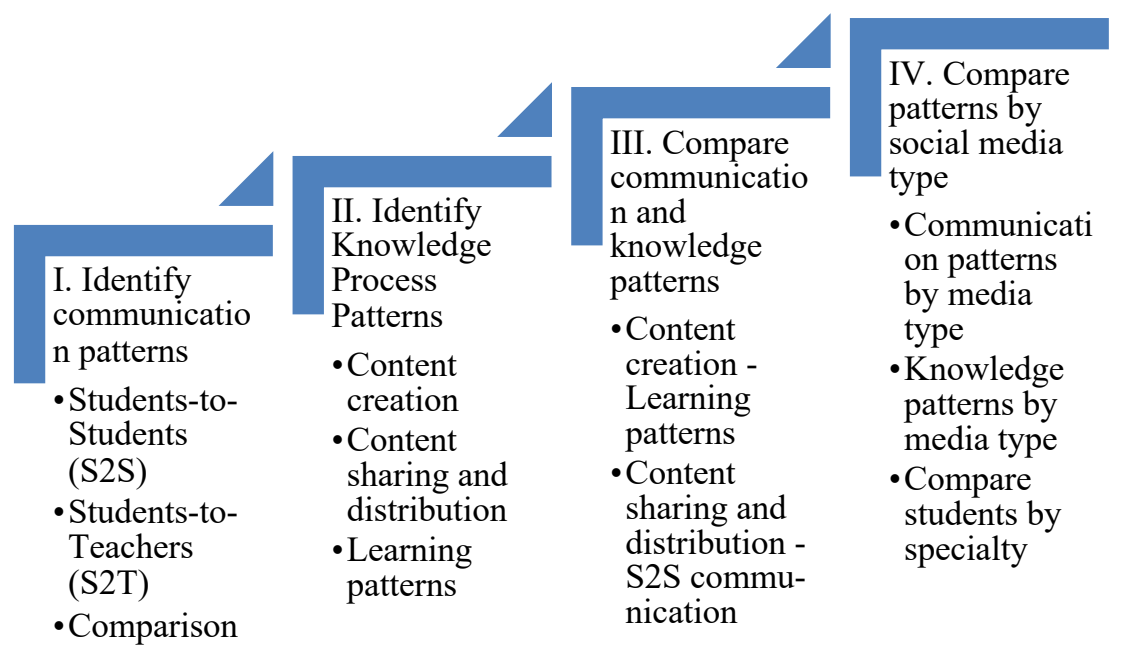

Fig. 2. Stages of research process of the study

Prior choosing and implementing appropriate methods we have defined some research questions regarding each stage of the research process. The research questions (RQ) are as follows:

\subsection{Identify communication patterns}

RQ1. What are the most used channels for students-to-students (S2S) and studentsto-teachers (S2T) communication?

RQ2. What are the most frequent combinations of channels in S2S and S2T communication?

RQ3. How many different channels do students use on average?

RQ4. Are there any differences between S2S and S2T communication in terms of used channels?

\subsection{Identify knowledge process patterns}

RQ5. What are the most used social media and e-resources during the process of content creation, content sharing, distribution and additional learning?

RQ6. What are the most frequent combinations of social media and e-resources used by students during the process of content creation, content sharing, distribution and additional learning? 
RQ7. How many different social media and e-resources do students use in the process of content creation, content sharing, distribution and additional learning?

RQ8. Are there any important association rules regarding knowledge patterns?

\subsection{Compare communication and knowledge patterns}

RQ9. What are the differences of patterns of usage of social media and e-resources for content creation and additional learning?

RQ10. Is there a similarity of communication channels used for S2S communication and social media and e-resources used for content sharing and distribution?

RQ11. How do students use typical e-resources like e-books and scientific databases compared to social media in the process of content creation and learning?

RQ12. How is the university learning management system used in the knowledge process compared to social media and e-resources?

\subsection{Compare patterns by social media type}

RQ13. What are the communication patterns by social media type?

RQ14. What are the knowledge process patterns by social media type?

RQ15. Are there any statistical significant relationships between specialty of the students and the application of certain social media types?

Based on the listed research questions we have chosen the association analysis as the most appropriate method for identifying patterns of usage. Association analysis was performed using Microsoft SQL Server Analysis Services with the supported Apriori algorithm. As an addition to this data mining method we've performed descriptive statistics such as frequency analysis, cross-tabulation, etc. A chi-square test for independence has been used for testing the relationships between students' specialty and the application of certain social media types in content creation, content sharing and distribution and learning process. Summarization and data visualization like column and pie charts was done in Microsoft Excel. Following the requirements of association analysis, the results from the online survey had to be transformed in two related tables-Students (the case table) and Results (the nested table)-before creating the mining structure.

Social media cover a wide range of technologies and applications and can be summarized in the following categories-communication, collaboration, knowledge management, multimedia, entertainment $[11,12]$. For each category many authors point out applications which typically can be included in the social media landscape: blogs (e.g. WordPress), content communities (e.g. YouTube), social networking sites (e.g. Facebook, LinkedIn), collaborative projects (e.g. Wikipedia), and virtual social worlds (e.g. Second Life) $[13,14]$.

Every association analysis was performed in two variants-once using the specific social media applications and once using social media type. To discover pattern in collected students' answers all investigated media tools in our research have been summarized as follows (table 1): 
Table 1. Types of social media and resources

\begin{tabular}{|l|l|}
\hline \multicolumn{1}{|c|}{ Media Types } & \multicolumn{1}{c|}{ Include } \\
\hline Social Networking site & Facebook, Twitter, Google+, Instagram, LinkedIn, Reddit \\
\hline Content Sharing Communities & YouTube, Flickr, Slideshare \\
\hline Forums & Not exactly specified (Forums) \\
\hline Collaborative Knowledge Management & Wikis \\
\hline Communication applications & Snapchat, Skype, Viber, WhatsApp, Messenger, etc. \\
\hline Learning Management Systems & E-Learn \\
\hline Knowledge Base & Scientific databases, E-books \\
\hline
\end{tabular}

Our study is not limited only to the use of social media in higher education. One area of interest is also the application of more traditional resources and services such as email, scientific databases and e-books in communication and/or knowledge process. The Email service can be added to typical Internet services, which is regularly used on a daily basis, but is increasingly being replaced by more socially-oriented media types of communication opportunities that are interactive and significantly faster. In our opinion, scientific databases like ResearchGate.net, Academia.edu, Science Direct, etc. have typical features of social networks, but students view and use them mainly as knowledge bases, that's why we've grouped them in knowledge base type along with e-books.

Undoubtedly the most used social network is Facebook. The possibility of sharing and communication between groups with similar interests is well realized through Facebook groups. Therefore, a point of interest is to measure the participation in academic related Facebook groups of students from one faculty or specialty. The application of social media and e-channels for communication is explored by relevant questions. The students had to point out also the used e-media resources for content creation, sharing and distribution as well as for additional learning (exam preparations, tests, course projects, etc.). Respondents (378 total) were randomly chosen amongst students from different bachelor and major programs and courses of education (from I to VI). Responses have been collected from May till June 2017.

\section{$4 \quad$ Results}

\subsection{Communication channels}

Facebook is definitely the most preferred social media. Nearly all respondents (97.4\%) have a Facebook profile and $88 \%$ use it on a daily basis. Our research confirms the assumption that most used tool for academic related communication is the Facebook group. Almost all students (97\%) participate in a Facebook group of specialty/department. As an evidence for the great level of usage of Facebook group can be pointed out the high percentage of students $(96 \%)$ that use it as a communication channel amongst them. For comparison, Facebook group is used only by $40.5 \%$ of respondents for students-to-teachers communication. Facebook group is also extensively used during the process of content creation and distribution. 
There are clear difference in the students' choice of channels for communication with academic staff and with their peers. The main differences are depicted on figure 3 . Students communicate with their teachers by more traditional channel as email (83\%). Relatively high is the percentage of students (40\%) who use eLMS functionalities like chat, messaging and discussion forums to communicate with the academic staff. Naturally the students use Facebook and particularly Facebook group to communicate with their colleagues as they're used to connect to all other friends from the social network.

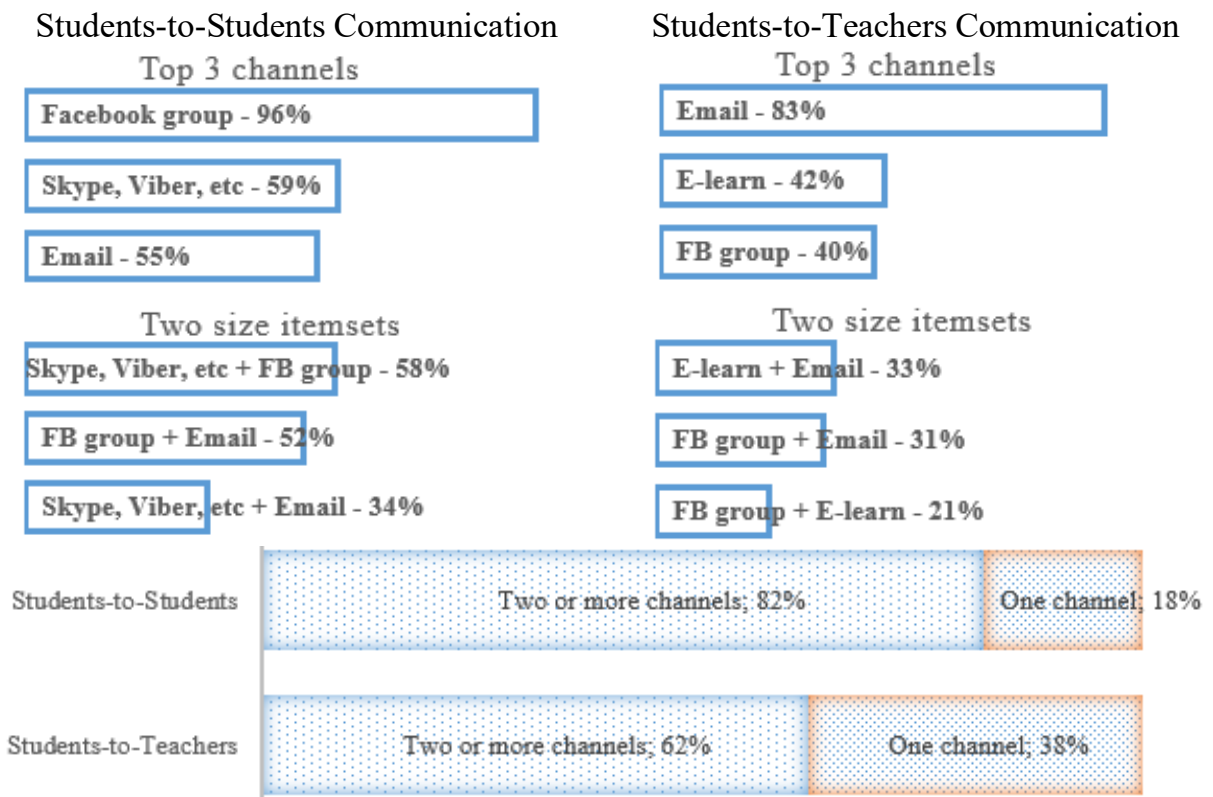

Fig. 3. Communication patterns in Student-to-Student and Student-to-Teacher communication

The majority of students $(82 \%)$ use more than one channel for communication among themselves, while a significantly smaller percentage $(62 \%)$ use two or more ways for conversation with educators. The Apriori association algorithm supported in Microsoft SQL Server Analysis Services was applied in this research in order to identify the most simultaneously used combination of channels for both forms of communication. The generated association rules were with relatively low importance, but useful knowledge was extracted from itemsets ordered by support (see on table 2).

\subsection{Knowledge process}

The most supported social media combinations used for content creation, sharing and additional learning were extracted with association rules algorithm and ordered by percentage of support (e.g. support divided by total number of cases).

Wikis are the most used for content creation. Nearly $3 / 4$ from students use this type of social media for this purpose with majority of students specifying Wikipedia as a 
main representative (see figure 4). Other preferable resources used during the process of content creation were scientific databases, Facebook groups, E-books, eLMS and community forums. The most supported two-size itemsets for content creation were scientific databases + Wikis (used in $37 \%$ of cases), E-books + wikis (37\%), and Ebooks + Scientific databases $(33 \%)$. The median value of count of resources used by a student for content creation is 3 .

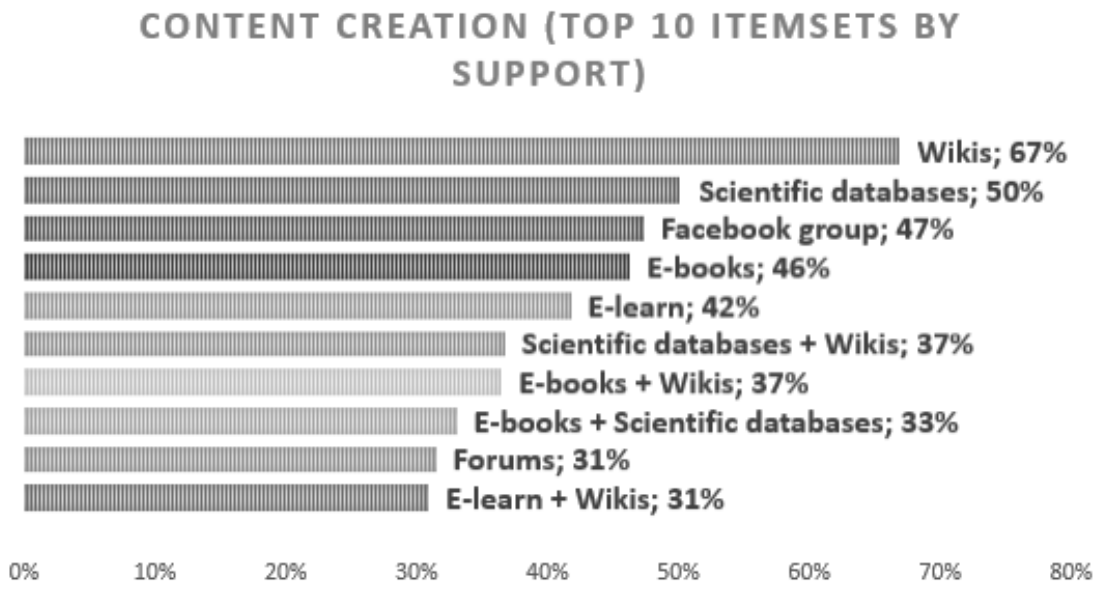

Fig. 4. Media and resources used for content creation

Facebook group is nearly four times (85\%) more frequently used for content sharing and distribution than the positioned on second and third place - eLMS $(23 \%)$ and Google $+(19 \%)$ (see figure 5). The most supported two-size itemsets are eLMS and Facebook group (18\% of cases), Wikis + Facebook group (16\%) and Google + + Facebook group (12\%).

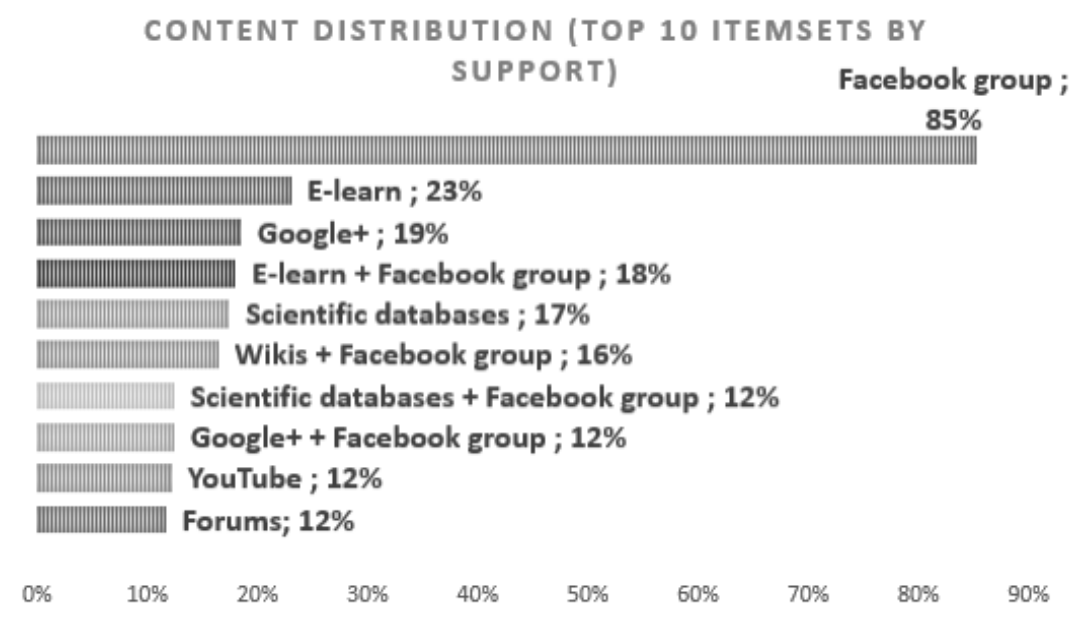

Fig. 5. Media and resources used for content sharing and distribution 
Students use various resources for additional learning and training for exams, course projects, seminars, tasks, etc. The most used resources are wikis ( $60 \%$ from all cases) as it is the case with content creation (see figure 6). The order of the most supported itemsets however differs slightly from that of resources used during the process of creating content (figure 4). Electronic Learning Management Systems (eLMS) are the second most supported itemset ( $48 \%$ of all cases) which is explained by the fact that this resource contains all the mandatory knowledge required for taking exams or developing course projects and tasks. Facebook group is the third popular media for additional learning meaning that students use collaboration and sharing opportunities of the social media also for additional learning. The popularity of Facebook groups is obvious not only in communication and content distribution as it is expected, but also as a popular resource for additional learning along with more traditional ones as wikis, eLMS and scientific databases.

On average, students use many resources simultaneously for additional learning with $83 \%$ using more than two and $61 \%$ using more than three different resources. The most supported two-size itemset is the couple of the two most used resources - wikis and eLMS are used simultaneously by $31 \%$ of the respondents. Close to this percentage is the relative support of itemsets e-books + wikis $(31 \%)$, scientific databases + wikis $(28 \%)$ and e-books + scientific databases $(27 \%)$.

\section{RESOURCES FOR ADDITIONAL LEARNING (TOP 10 ITEMSETS BY SUPPORT)}

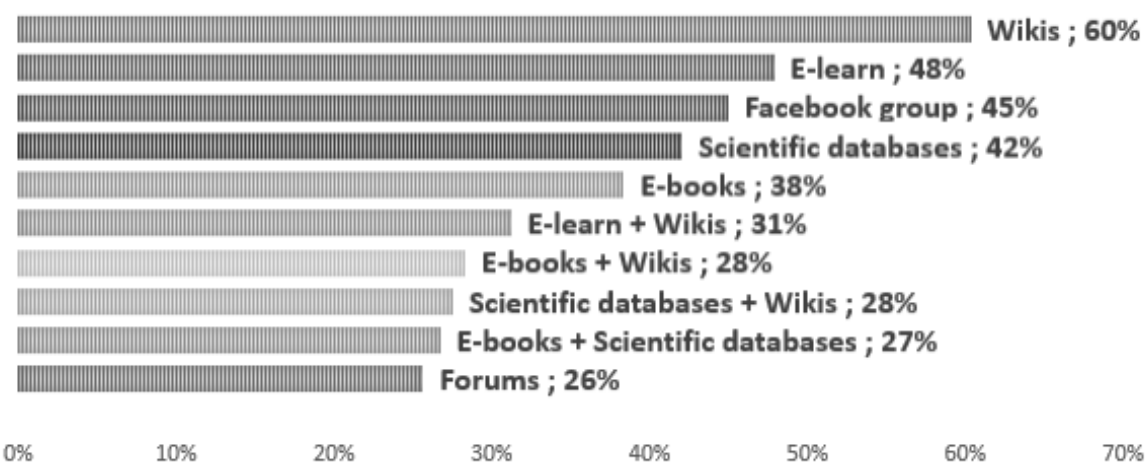

Fig. 6. Media and resources used for additional learning for exams, course projects, etc.

\subsection{Comparison of communication and knowledge process patterns}

The comparison of communication and knowledge patterns was performed by association analysis where the nested table was produced by adding together answers to questions regarding media and channels used for S2S and S2T communication. Similarly, the nested table for knowledge process patterns combined all the answers about used social media and resources during content creation, learning and content sharing and distribution. The results are summarized in table 2 . 
As it is shown in the table, $80 \%$ from students use simultaneously email for S2T communication and Facebook group for S2S communication. This is $30 \%$ higher than the second most used combination of communication channels - communication applications (Skype, Viber, WhatsApp, etc.) for S2S, and email for S2T communications.

Association rules for communication patterns proved to be with relatively low importance, since the main trends are clear - FB group is used for S2S and email for S2T communication. Nevertheless, we've included some interesting rules, e.g. "Students, who use LinkedIn and eLMS for S2S communication, also use Twitter for S2T communication", "Students who communicate with their colleagues by Twitter and eLMS, also use LinkedIn for communication with their teachers".

The research of the used social media and e-resources for the knowledge process (content creation, content sharing and distribution, learning) revealed the most used simultaneously resources. The prevailing part (58\%) of them use wikis for content creation and Facebook group for content sharing and distribution. Facebook as a media both for content creation and sharing is used by $44 \%$ from the students. Relatively high is the percentage of students $(38 \%)$, who prefer e-books for content creation and Facebook group for content sharing. The most supported 3-size itemset include e-books and wikis for content creation and Facebook group for content sharing and distribution. This once again proves the dominant role of Facebook as a media for content sharing and communication among students.

Table 2. Summarized results from association analysis

\begin{tabular}{|c|c|c|}
\hline \multicolumn{3}{|c|}{ Communication patterns } \\
\hline \multirow{3}{*}{$\begin{array}{l}\text { Most supported item- } \\
\text { sets ( } 2 \text { and more items) }\end{array}$} & S2T Email, S2S FB group & $80 \%$ of the cases \\
\hline & S2S Skype, Viber, etc., S2T Email & $51 \%$ of the cases \\
\hline & S2S Skype, Viber, etc., S2T Email, S2S FB group & $50 \%$ of the cases \\
\hline \multirow{3}{*}{ Some important rules } & S2S LinkedIn -> S2T Twitter & Lift 2.45, prob 1 \\
\hline & S2S Twitter, S2S E-Learn -> S2T LinkedIn & Lift 2.13 , prob 0.8 \\
\hline & S2S LinkedIn, S2T E-Learn -> S2T Twitter & Lift 2.35 , prob 0.7 \\
\hline \multicolumn{3}{|c|}{ Knowledge process patterns } \\
\hline \multirow{6}{*}{$\begin{array}{l}\text { Most supported item- } \\
\text { sets ( } 2 \text { and more items) }\end{array}$} & Creation Wikis, Sharing FB group & $58 \%$ of the cases \\
\hline & Creation FB group, Sharing FB group & $44 \%$ of the cases \\
\hline & Creation Scientific databases, Sharing FB group & $42 \%$ of the cases \\
\hline & Creation E-books, Sharing FB group & $38 \%$ of the cases \\
\hline & Creation E-Learn, Sharing FB group & $37 \%$ of the cases \\
\hline & Creation E-books, Creation Wikis, Sharing FB group & $31 \%$ of the cases \\
\hline \multirow{3}{*}{ Some important rules } & Sharing Slideshare, Learning E-Learn -> Learning Slideshare & Lift 2.59 , prob 0.8 \\
\hline & $\begin{array}{l}\text { Creation Slideshare, Learning E-books -> Learning } \\
\text { Slideshare }\end{array}$ & Lift 2.45 , prob 0.7 \\
\hline & Sharing Slideshare, Learning Wikis -> Learning Slideshare & Lift 2.12 , prob 0.8 \\
\hline
\end{tabular}

Some notable rules derived form association analysis are related to using Slideshare as a social media for content creation and sharing. Students who use Slideshare for content creation and sharing, also use this media for additional learning. It is worth mentioning that these students also use eLMS, e-books or wikis for learning as shown in table 2. 


\subsection{Exploring patterns by social media type}

To aggregate the use of different channels, media and resources they're grouped by type, as it is shown in table 1. The most used social media type are the social networking sites with the leader Facebook. Social networking sites are used for content sharing by $91 \%$ of students (figure 6). The next most used media type in the knowledge process are collaborative knowledge management platforms (e.g. wikis), used by $67 \%$ of students for content creation and $60 \%$ of students for learning. Knowledge bases, such as scientific databases and e-books, give in to social networking sites and collaborative knowledge management regarding the knowledge management process. Knowledge bases are surpassed by collaborative management social media and are used approximately equal with social networking sites for content creation and learning. In our opinion this illustrates one important trend regarding the knowledge process from the past several years - the shift from more traditional e-resources like scientific databases and e-books toward social media types like social networking sites and collaborative knowledge management.

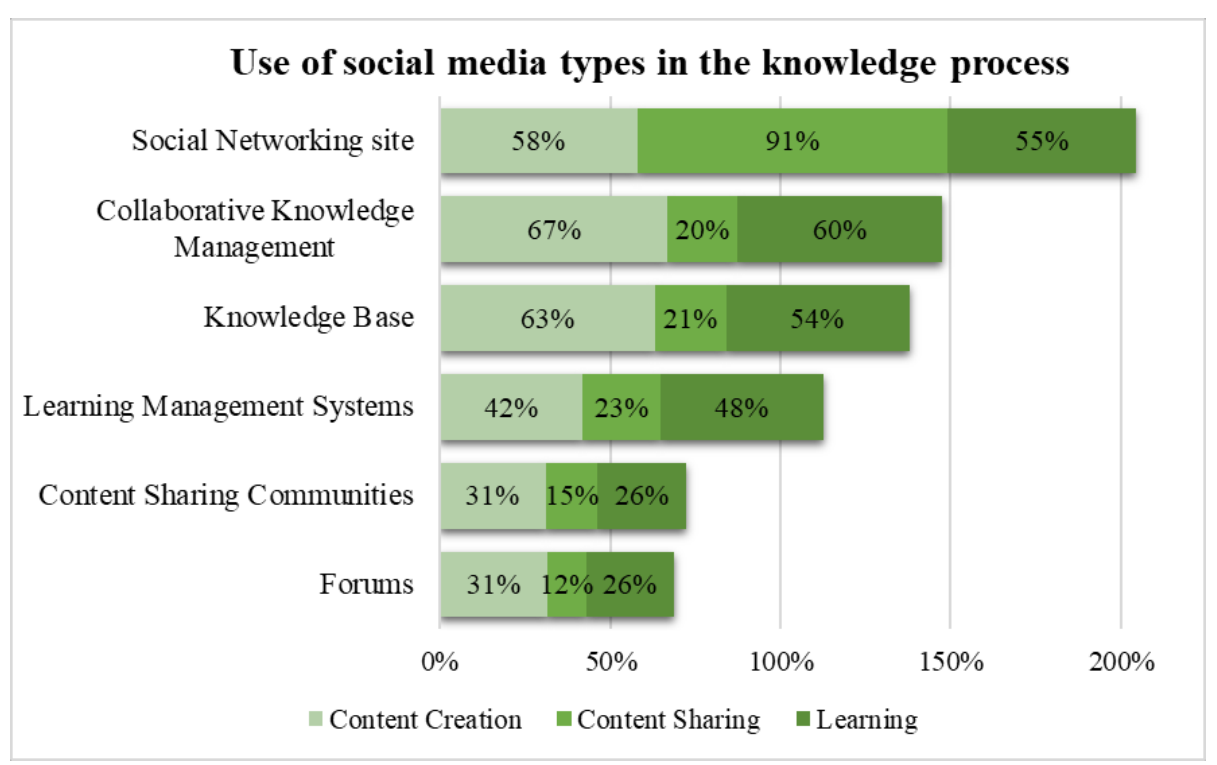

Fig. 7. Use of social media and e-resources type shown as percentage of students

Following RQ15, defined in the method section of this article, a chi-square test for independence was performed for estimating the relationships between students' specialty and used social media and resources for content creation, sharing and learning. Respondents' specialties were grouped according to professional area of their specialties, namely Computer Science and Economics. Although the specialty "Business Information Systems" is in Economics professional area the curriculum is more closely related to curriculum of Informatics specialty. This gives us the ground to group both Business Information Systems and Informatics in Computer Science group. Most tests 
showed no significant relationships between students' specialty and used social media type, except for the application of communities and forums for content creation and sharing.

The chi-square test for independence with continuity correction of Yates indicated a statistically significant medium relationship between specialty and the usage of content sharing communities as a content creation media $\left(\chi^{2}(1, \mathrm{~N}=378)=31.327, \mathrm{p}<0.001\right.$, phi $=0.3$ ). The crosstab showed that $43 \%$ of students from Computer Science use content sharing communities compared to only $16 \%$ of students from Economics. A little more than $2 / 3$ from all the students who've been using content sharing communities are from Computer Science Department.

A similar relationship was found between students' professional area the application of content sharing communities for content sharing and distribution $\left(\chi^{2}(1, \mathrm{~N}=378)\right.$ $=14.280, \mathrm{p}<0.001$, phi $=0.22$ ). From all the students who used content sharing communities for content sharing and distribution, $80 \%$ are students in Computer Science area, while only $20 \%$ are from Economics.

The professional area of the students' specialty is related also to the usage of forums for additional learning. The chi-square test for independence with Yates correction showed a statistical significant although small relationship $\left(\chi^{2}(1, N=378)=4.407\right.$, $\mathrm{p}=0.027$, phi $=0.2$ ). Forums are used by $30 \%$ of the students in Computer Science which is $2 / 3$ from all the students who used forums as a learning media. At the same time, only $20 \%$ of the students in economics used forums for this purpose.

Based on results from chi-square tests it can be assumed that content sharing communities like Slideshare, YouTube, etc. and forums for content creation, sharing and learning are more likely to be used by students in technology oriented specialties like Computer Science compared to Economics specialties. Regarding the application of social networking sites, E-Learn, collaborative knowledge management and knowledge bases there isn't statistically significant relationship regarding students' specialties.

\section{Conclusion and Future Work}

The results from the online survey reveal some notable trends in using social media in higher education. Some of the main findings can be summarized as follows:

- Students proactively use various social media tools and channels in communication regarding the educational process. However, there are different communication patterns when comparing S2T and S2S communication. Students use Facebook groups and communication applications (Skype, Viber, etc.) when communicating with their colleagues, while the more preferable channels for communication to their teachers are email and eLMS platforms;

- Electronic Learning Management Systems are less used than wikis for exam preparations, course tasks and projects. Wikis and especially Wikipedia is the most used social media during the process of content creation, sharing and learning;

- The majority of students are members in academic related Facebook groups and use them not intensively only for communication with their peers but also for content distribution and learning; 
- Wikis and social networking sites (Facebook, Google+, Twitter, etc) are preferable than scientific databases and e-books for learning and content creation;

- University learning management systems yield to social networking sites, wikis and knowledge base as a preferable media for content creation and learning;

- There aren't any significant relationships between students' specialty and the way they use different social media type in the knowledge process. However, there is an exception regarding the use of content sharing communities and forums where a more intensive usage is found for students in Computer Science compared to Economics.

These research results lead to a conclusion that the usage of social media in higher education is mostly initiated by students. The current research focus on students' view and their assessment of the application of various social media in the higher learning. A further study is due to explore the role of educational institutes and teachers in the process of application of social media in the universities.

\section{References}

[1] Statista. (2018). Distribution of Facebook users worldwide as of July 2018, by age and gender. Retrieved 10 7, 2018, from Statista. The Statistics Portal: https://www.statista.com/ statistics /376128/facebook- global-user-age-distribution/

[2] Dumpit, D.Z., Fernandez, C.J. (2017). Analysis of the use of social media in higher education Institutions (HEIs) using the Technology Acceptance Model, International Journal of Educational Technology in Higher Education, vol. 14, issue 1, article number 5, 2017. https://doi.org/10.1186/s41239-017-0045-2

[3] Liu, L., Zhang, L., et al. (2018). Influencing Factors of University Students' Use of Social Network Sites: An Empirical Analysis in China. International Journal of Emerging Technologies in Learning. vol.13, issue 3, 2018. https://doi.org/10.3991/ijet.v13i03.8380

[4] Lau, W.F. (2017). Effects of social media usage and social media multitasking on the academic performance of university students, Computers in Human Behaviour, Volume 68, pp.286-291, 2017. http://dx.doi.org/10.1016/j.chb.2016.11.043

[5] Manca, S. \& Ranieri, M. (2016). Facebook and the Others. Potentials and obstacles of social media for teaching in higher Education, Computers and Education, vol.95, pp.216-230, 2016. http://dx.doi.org/10.1016/i.compedu.2016.01.012

[6] Chawinga, W.D. (2017). Taking social media to a university classroom: teaching and learning using Twitter and blogs, International Journal of Educational Technology in Higher Education, vol.14, issue 1, article number 3, 2017. https://doi.org/10.1186/s41239-017-0041-6

[7] Tang, Y. \& Hew, K.F. (2017). Using Twitter for Education: Beneficial or simply a waste of time? Computers and Education, volume 106, pp.97-118, 2017. https://doi.org/10.10 16/j.compedu.2016.12.004

[8] Moore-Russo, D., Radosta, M., Martin, M. \& Hamilton, S. (2017). Content in context: analyzing interactions in a graduate-level academic Facebook group, International Journal of Educational Technology in Higher Education, volume 14, issue 1, 2017. https://doi.org/10.1186/s41239-017-0057-y

[9] Jeljeli, R., Alhaji L., Khazam, K. A (2018). Comparison between Moodle, Facebook, and Paper-based Assessment Tools. International Journal of Emerging Technologies in Learning. Vol.13, issue 5, pp.86-99, 2018. https://doi.org/10.3991/ijet.v13i05.8091 
[10] Arouri, Y. (2015). How Jordanian University Students Perceive the Opportunities and Challenges of Using Facebook as a Supplementary Learning Resource? International Journal of Emerging Technologies in Learning. Volume 10, issue 1, pp 46-54, 2015. http://dx.doi.org/10.3991/ijet.v10i1.4265

[11] Fabian, R. (2011). Kundenkommunikation über Social Media: ein Planungsprozess. Josef Eul Verlag, Lohmar - Köln

[12] Kilian, K. (2010). Was sind Social Media? Absatzwirtschaft, 3, p. 61.

[13] Balakrishnan, V., \& Gan, C.L. (2016). Students' learning styles and their effects on the use of social media technology for learning. Telematics and Informatics, 33(3), 808-821. https://doi.org/10.1016/j.tele.2015.12.004

[14] Kaplan, A.M., Haenlein, M. (2010). Users of the world, unite! The challenges and opportunities of Social Media. Business Horizons, 53(1), 59-68. https://doi.org/10.10 $\underline{16 / j . b u s h o r .2009 .09 .003}$

\section{$7 \quad$ Authors}

Yanka Aleksandrova is a Chief Assistant Professor at the Department of Computer Science on the Faculty of Informatics at University of Economics - Varna. She acquired her $\mathrm{PhD}$ degree in the same university in 2016. Her interests include machine learning, business intelligence, social media, and design of information systems. Currently she participates in scientific project exploring the application of social media in business and education. Email: yalexandrova@ue-varna.bg

Silvia Parusheva acts as an Associated Professor at the Department of Computer Science on the Faculty of Informatics at University of Economics - Varna. She graduated with a PhD from the same University in 2001. Her scientific interests are in the field of E-business, E-learning, social media, information systems. She runs a scientific project exploring the application of social media in business and education. She is a reviewer for several journals and for various conferences in the field of Information Technologies and Computer Sciences. Email: parusheva@ue-varna.bg

Article submitted 2018-10-16. Resubmitted 2018-11-22. Final acceptance 2018-11-23. Final version published as submitted by the authors. 